\title{
Identification of Techno-Economically Viable Crop Residue Utilization in India
}

\author{
Shahabaddine Sokhansanj ${ }^{*}$, Yogender Kumar Yadav², Anthony Lau ${ }^{1}$, \\ Yadvika², Mahmood Ebadian', Kanishk Verma² \\ ${ }^{1}$ University of British Columbia, Vancouver, Canada \\ ${ }^{2}$ CCS Haryana Agricultural University, Haryana, India \\ Email: ^Shahab.Sokhansnaj@ubc.ca
}

How to cite this paper: Sokhansanj, S., Yadav, Y.K., Lau, A., Yadvika, Ebadian, M. and Verma, K. (2021) Identification of Techno-Economically Viable Crop Residue Utilization in India. Journal of Sustainable Bioenergy Systems, 11, 94-104. https://doi.org/10.4236/jsbs.2021.112007

Received: March 9, 2021

Accepted: June 20, 2021

Published: June 23, 2021

Copyright $\odot 2021$ by author(s) and Scientific Research Publishing Inc. This work is licensed under the Creative Commons Attribution International License (CC BY 4.0).

http://creativecommons.org/licenses/by/4.0/

\begin{abstract}
India generates more than 140 million tonnes of surplus crop residue every year In Haryana, the agricultural sector alone produces 24.64 million tonnes of residue annually; of which only $71 \%$ is consumed in various domestic and commercial activities within the state. The rest of the material is burned causing severe contamination of air with smoke. There is an urgent need to identify suitable and sustainable conversion technologies that are efficient, eco-friendly as well as cost-effective for managing the huge available biomass not only in the state but also in the country. This paper reviews briefly the available crop residue and quantities burned, proposes a scheme to incorporate part of the residue in the field for its fertilizer value. The remaining biomass is harvested for animal feed and the excess is converted to bioenergy and biofuels. Among the developed and developing biofuels, the paper identifies biogas production from biomass for on-farm use. Pelletization is identified as an enabling technology to provide high quality feedstock for conversion to heat/power and in near future to advanced biofuels.
\end{abstract}

\section{Keywords}

India, Crop Residue, Crop Burning, Environment, Harvest, Collection, Pellets, Biogas, Techno-Economic, Advanced Biofuels

\section{The Blessing and the Curse of Crop Residue}

The blessing of crop residue is in its capacity to provide a source of affordable and easy accessible energy for every-day living essentials [1]. The curse of the crop residue is in its interference with a smooth transitioning from one crop to the next during the harvest and planting season [2]. India experiencing an 
un-precedent green revolution since mid-sixties. The increase in crop productivity has been largely due to an increase in yield and double cropping practices. Increased yield in grain has increased the available non-grain biomass. For rice crop, the ratio of the above ground biomass to grain is 1.5 to 2 . Mechanical or manual harvest practices leave a tall stubble of at least $150 \mathrm{~mm}$ tall in the field [2]. The higher yield and double cropping have forced the farmer to engage in an intense race to remove rice stalks immediately from the field in order to prepare the land to sow the following wheat seeds. The farmers in Haryana and Punjab have 4 - 5 weeks to complete harvesting and begin sowing.

Mechanical chopping and incorporation of chopped rice into soil and seeding in stubble with happy seeder have helped in dealing with excess rice straw [3]. However, the economics of owning the equipment and a slow speed of operations have not solved the problem of excess straw. Farmers often resort to burning the residue to cope with the shortage of time in cleaning the field. The images in Figure 1 show that crop residue burning in Punjab and Haryana within a span of three days in the last part of October 2020. Many of the pollutants found in large quantities in biomass smoke are known or suspected carcinogens and could lead to various air borne/lung diseases. The pictures are testimony to the fact that the current policies and regulations for lessening the burning of biomass are not working to their full potential. Crop burning is not limited to Punjab and Haryana. Table 1 lists the major states that produce crop residues. Uttar Pradesh generates nearly 60 million tonnes $(t)$ out of which 13.34 million $t$, or almost all surplus crop residue are burned. Punjab at more than 50 million $\mathrm{t}$ ranks second. The State of Haryana with 27.83 million $t$ ranks $10^{\text {th }}$ in the list. Punjab is the first and Haryana the fourth in crop residue surplus. It is estimated that in Haryana, $10 \%$ of the straw is harvested by hand and $90 \%$ is combined harvested.

Roughly $55 \%$ of the machine harvested rice is completely burned and the rest

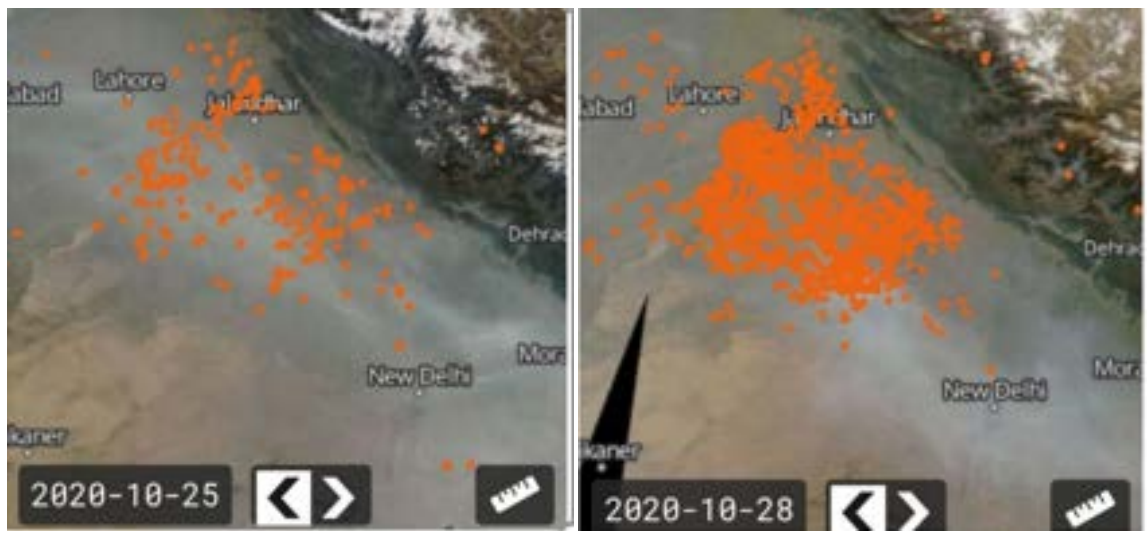

Figure 1. NASA images show sudden rise in stubble burning cases in Punjab, Haryana; Increase in crop fires during a sequence of 5 days from October 25 to October 30, 2020. Source:

https://www.timesnownews.com/india/article/nasa-images-show-sudden-rise-in-stubbleburning-cases-in-punjab-haryana/675543. 
are partially burned. Although data in Table 1 has a few anomaly (e.g. West Bengal) but it highlights the huge amount of biomass, 91.75 million $t$ that is burned each year in India. That is a lot of bioenergy that goes into smoke. The burning of paddy straw leads to loss of precious nutrients as nearly $25 \%$ nitrogen and phosphorus, $50 \%$ sulfur and $75 \%$ of potassium uptake from soil are retained in the crop residues. It has been estimated that burning of 1 tonne of paddy straw accounts for loss of $5.5 \mathrm{~kg}$ nitrogen, $2.3 \mathrm{~kg}$ phosphorus, $25 \mathrm{~kg}$ potassium and $1.2 \mathrm{~kg}$ sulfur [4].

\section{Energy Content of Crop Residue}

In all India, $26 \%$ of the rural households use crop residues while $64 \%$ rely on wood fuel. Much of the crop residues about $45 \%$ are used as animal feed, fuel, and in various industrial processes [2]. Only $12.2 \%$ of the crop residue is used for energy production. The calorific value of the crop residue ranges from 15.1 $\mathrm{MJ} / \mathrm{kg}$ for oilseed stalks to $17.47 \mathrm{MJ} / \mathrm{kg}$ for cotton stalks with an average of 16.5 $\mathrm{MJ} / \mathrm{kg}$ based on the dry biomass. The amount of heat energy and power production from excess biomass can be estimated from the annual available biomass

Table 1. Inventory of crop residues, surplus and burned in India [7] [8].

\begin{tabular}{|c|c|c|c|}
\hline States & Crop residue generation & Crop residue surplus & Crop residue burned \\
\hline Uttar Pradesh & 59.97 & 13.53 & 21.92 \\
\hline Punjab & 50.75 & 24.83 & 19.62 \\
\hline Maharashtra & 46.45 & 14.67 & 7.41 \\
\hline West Bengal & 35.93 & 4.29 & 4.96 \\
\hline Karnataka & 33.94 & 8.98 & 5.66 \\
\hline Rajasthan & 29.32 & 8.52 & 1.78 \\
\hline Gujarat & 28.73 & 8.9 & 3.81 \\
\hline Haryana & 27.83 & 11.22 & 9.06 \\
\hline Bihar & 25.29 & 5.08 & 3.19 \\
\hline Odisha & 20.07 & 3.68 & 1.34 \\
\hline Tamil Nadu & 19.93 & 7.05 & 4.08 \\
\hline Assam & 11.43 & 2.34 & 0.73 \\
\hline Chhattisgarh & 11.25 & 2.12 & 0.83 \\
\hline Kerala & 9.74 & 5.07 & 0.22 \\
\hline Jharkhand & 3.61 & 0.89 & 1.10 \\
\hline Uttarakhand & 2.86 & 0.63 & 0.78 \\
\hline Himachal Pradesh & 2.85 & 1.03 & 0.41 \\
\hline Jammu and Kashmir & 1.59 & 0.28 & 0.89 \\
\hline Remaining 8 States & 3.12 & 0.55 & 0.41 \\
\hline India & 501.76 & 140.84 & 92.81 \\
\hline
\end{tabular}


times the heat energy content of the biomass times the efficiency of converting that energy into electricity. Using this calculation, the amount of crop burned in India at 92.81 million $\mathrm{t}$ (Table 1 ) will have the potential to produce 1531.37 million GJ or 36.46 million $t$ oil equivalent ( $\mathrm{t}_{\mathrm{oe}}$ ' oil has roughly $42 \mathrm{GJ} /$ toe). According to EIA, the primary annual energy consumption in India has nearly tripled between 1990 and 2018, reaching an estimated 916 million toe [5]. The energy use pattern by Indian national shows that more than $27 \%$ of energy in the country comes from biomass and waste materials. Diverting burned crop residue to useful energy will contribute another $4 \%$ to the energy mix [5].

\section{Potential Solutions for Excess Crop Residues in India}

Dr. Ram Chandra [6] proposed two solutions to deal with excess rice straw: 1) on-site utilization and management that would consist of incorporating crop residue in the soil, animal feeding, and minor applications for various purposes; 2) off-field utilization that would consist of direct combustion for heat, power, ethanol production, and biogas production. Identification of techno-economically viable biomass conversion technologies for crop residue management will lead to few emerging areas of development in the value chain of biofuel and biomass energy technologies. A few of these technologies are associated with the first generation of biofuels like biodiesel, bioethanol, biogas, biomass gasification, and municipal waste pyrolysis.

Figure 2 is a proposed strategy for post-harvest handling of straw to minimize burning and to increase utilization of crop residue. Land application and collecting/removing of biomass are encouraged. The hand harvested and baled biomass are fed to animal feed, produce biogas, or converted to pellets. Pelletization is the central operation in extending the use of biomass to downstream. Once pelletized, the biomass is bagged and stored for shipping to heat and/or power application and more advanced liquid and gaseous fuels. A portion of pellets can be roasted to produce charcoal/biochar for energy and land applications.

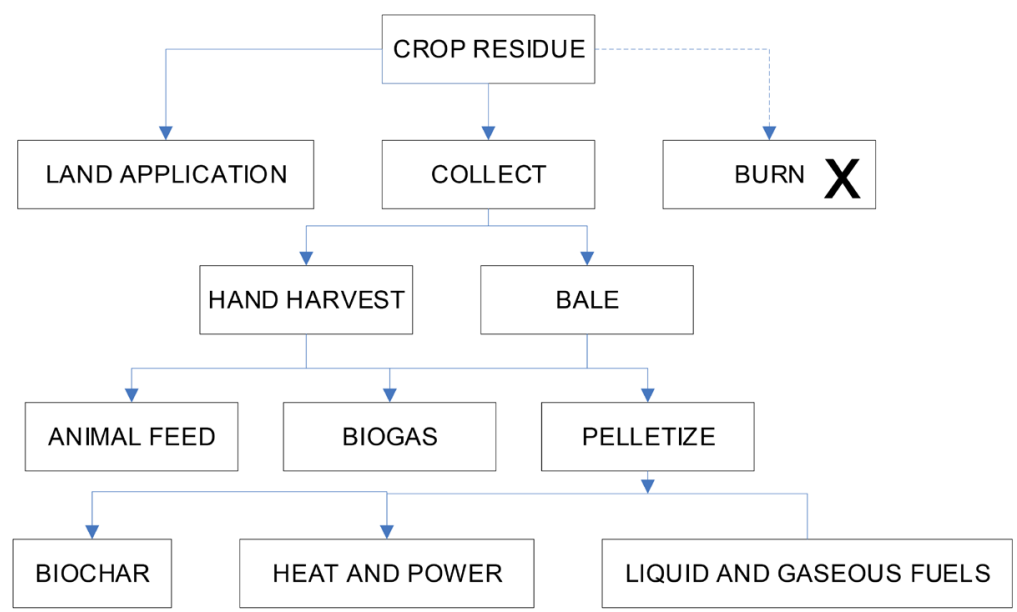

Figure 2. Proposed strategies for reduction of burning crop residue by taking advantage of progress in harvesting equipment and conversion technologies. 
Reference [2] suggests a combination of distributed and centralized processing operation for the growth of bioenergy at scale.

Figure 3 lists the current state of technologies that use biomass feedstock. TR (technology readiness) is the developmental state of each technology. Combustion technology at TR 9 are the oldest technology that is relatively well-developed. Pellets and briquettes have an improved combustion properties compared to lose biomass. Devices and pelletized biomass can burn biomass efficiently with the least emissions. Roasting biomass at temperatures $200^{\circ} \mathrm{C}-300^{\circ} \mathrm{C}$ in the absence of or a reduced oxygen increases the carbon content and enhances the calorific value of the biomass [9].

Large scale (production rate $>45,000 \mathrm{t}$ ) of producing torrefied biomass or biochar is not commercially available [10]. The cost of making torrefied biomass is a barrier against full scale commercialization of the product. Higher temperature gasification and pyrolysis of biomass are practiced but still at a pilot demonstration scale. Research and demonstrations are underway to convert the syngas from gasification to biomethane. The production of lignocellulosic ethanol and sustainable aviation fuel (SAF), and marine fuels are in the research and development stage. Advanced fuels will be discussed further in the following section.

\section{Brief Assessment of Conversion Technologies}

\subsection{Advanced Biofuels}

The European Commission Reports [12] [13] conclude that biofuels will remain more expensive than fossil fuels (with rare exceptions) unless the costs of mitigating climate change are going to be factored in. The cost of biofuels in Figure 4 is mainly governed by the cost of the feedstock and cost of capital (the investment). A barrel crude oil (42 US gallons) has an equivalent calorific value of 6.1 GJ. At an average of $55 \mathrm{USD} /$ Barrel, the feedstock cost for petroleum derived products amounts to $9 \mathrm{USD} / \mathrm{GJ}$. Figure 4 shows that biomethane from waste streams and biogas (anaerobic digestion) has at present the lowest cost at 12 USD/GJ but the reported cost of the same fuel can be as high as 54 USD/GJ.

Hydrotreated Vegetable Oils (HVO) has a production cost in the range of 18 $46 \mathrm{USD} / \mathrm{GJ}$ subject to the cost of the feedstock. The production cost of cellulosic ethanol is estimated in the range of $30-60 \mathrm{USD} / \mathrm{GJ}$. Biomethane, methanol,

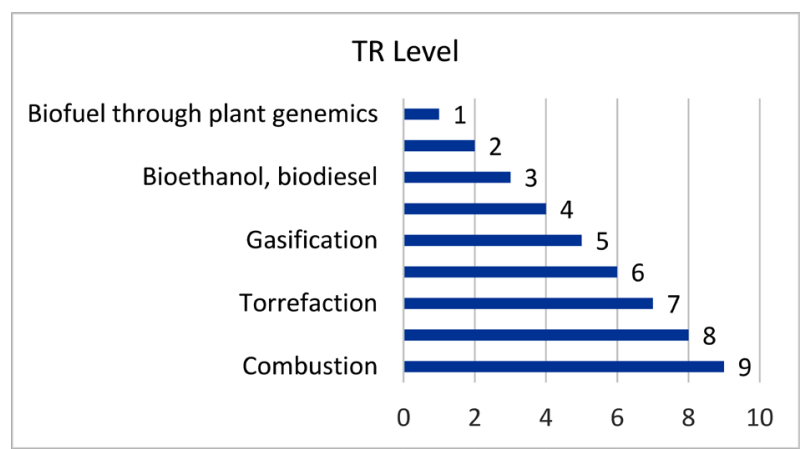

Figure 3. Technology readiness (TR) of biomass conversion processes [11]. 


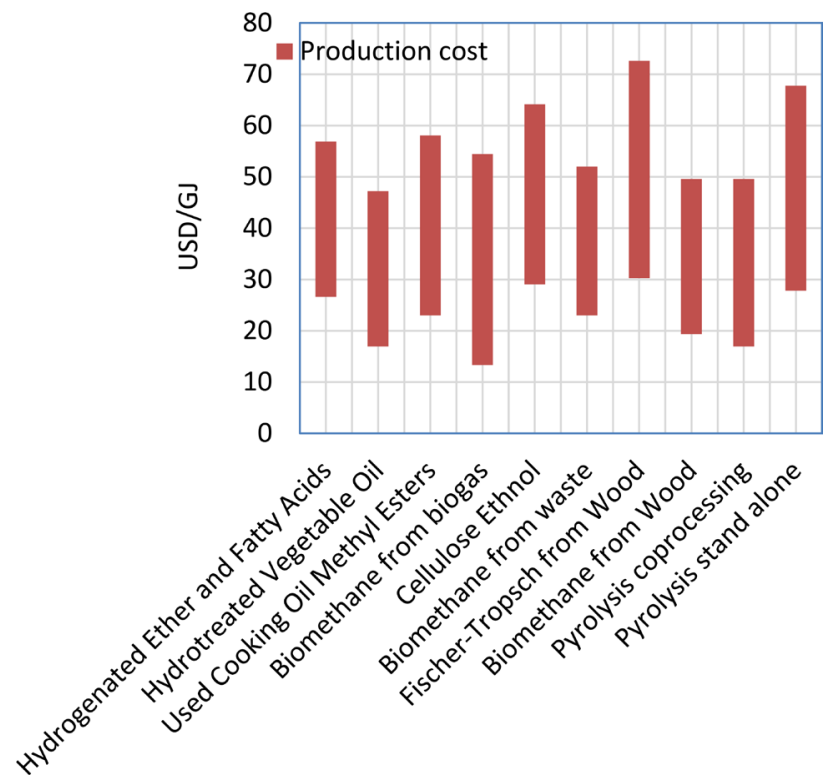

Figure 4. Range of production cost of advanced [18].

ethanol and DME from waste and biomass via gasification have a production cost of $22-52$ USD/GJ. The value chains based on waste streams with zero or negative cost offer possibilities for competitive cost production at present. Transport fuels via the FT process have the highest range as well as the highest minimum and maximum cost at $31-72 \mathrm{USD} / \mathrm{GJ}$ subject to the feedstock cost and comparably high investment intensity.

References [12] [13] collected data on the investment intensity (USD/G) product produced). The range of capital investment ranged from 480 to 850 USD $/ \mathrm{kW}$ for converting used cooking oil and vegetable oil to biodiesel. The required capital jumped to 3000 - $5500 \mathrm{USD} / \mathrm{kW}$ for cellulosic bioethanol. Investment for bio-methane from biogas has a narrow range around $1800 \mathrm{USD} / \mathrm{kW}$. The authors [12] [13] concluded that a low investment intensity combined with high conversion efficiency generally leads to a low overall production cost. The plant size and the economy of scale play a crucial role in the economics of the advanced biofuels. Bioethanol and gasification plants are usually in 100's of MW whereas bio-methane from biogas plants are much smaller in the range of 10's MW capacity.

\subsection{Pelletization}

There is a growing market for granulated biomass in the form of pellets for international and domestic purposes. Pellets offer advantages such as easy storage and transport, a lower pollution and dust than unprocessed bulky biomass. In India, Agricultural pellets are manufactured in several types and grades as fuels for electric power plants, homes, and other applications [14]. Pellet-making machineries are available in the market in a variety of sizes and scales, which allows their manufacture at domestic as well industrial-scale production. Pellets have a cylindrical shape and are about $6-8 \mathrm{~mm}$ in diameter and $6-24 \mathrm{~mm}$ in 
length having density 1100 to $1300 \mathrm{~kg} / \mathrm{m}^{3}$ as compared to $30-150 \mathrm{~kg} / \mathrm{m}^{3}$ for loose biomass. Manufacturing pellets offer opportunities to automate the delivery of the pellets to the combustion or other reacting chambers [15].

Pellet production cost vary widely depending on feedstock prices, the form of biomass received at the plant, initial moisture content of biomass and whether drying is needed. Table 2 lists the investment cost, annual fixed and operating variables and the specific cost of biomass for each operation. An Indian manufacturer provided the capital equipment costs for chipper, dryer, hammer mill, and pellet press. We calculated the balance of equipment and operations using the equipment and rates published in literature for Europe and North America [16] [17]. The pellet throughput for the baseline was $5 \mathrm{t} / \mathrm{h}$. The ratio of throughputs and a scale factor of 0.6 were assumed to scale down the $5 \mathrm{t} / \mathrm{h}$ to 1 $\mathrm{t} / \mathrm{h}$.

The initial and final moisture content was assumed 30\% and 6\% wet mass basis. The price of raw biomass was assumed 7 USD/t. The lifetime of equipment was assumed 15 years and the life time of buildings was assumed 50 years. An interest rate of $6 \%$ was applied to calculate the capital cost recovery factor. Table 2 lists the cost of $1 \mathrm{t}$ of pellet at 70.63 USD. The sum of the cost of dryer and storage was $30 \%$ of the total cost. The production cost of $1 \mathrm{t}$ of pellet would be around 43.52 USD when drying and storage costs are not included. The calculations assumed $7.69 \mathrm{USD} / \mathrm{t}$ for the cost of feedstock and $3.80 \mathrm{USD} / \mathrm{h}$ for the labor.

\subsection{Biogas}

Anaerobic digestion (AD) is the decomposition of organic matter in the absence of oxygen. During this decomposition, which is due to microbial activity, a

Table 2. Estimating the cost (USD) of producing 1 tonne/hr of pellets.

\begin{tabular}{ccccc}
\hline Operations-Equipment & $\begin{array}{c}\text { Capital } \\
\mathbf{( \$ )}\end{array}$ & $\begin{array}{c}\text { Fixed } \\
(\$ / \mathbf{y})\end{array}$ & $\begin{array}{c}\text { Variable } \\
(\$ / y)\end{array}$ & $\begin{array}{c}\text { Unit cost } \\
\text { (\$/tonne) }\end{array}$ \\
\hline Dripper/shredder & 10,852 & 1422 & 24,308 & 1.82 \\
Hammer mill & 38,095 & 20,820 & 188,631 & 15.38 \\
Pellet press & 12,442 & 4959 & 23,528 & 2.25 \\
Cooler & 20,382 & 10,437 & 87,317 & 7.23 \\
Storage & 20,304 & 2659 & 3980 & 0.65 \\
Peripheral equipment & 690,617 & 74,949 & 16,478 & 11.73 \\
Total Equipment & 277,395 & 36,328 & 38,185 & 7.83 \\
Construction & $1,070,086$ & 151,574 & 382,428 & 46.88 \\
Mobile equipment & 472,776 & 49,824 & 1907 & 6.88 \\
Raw biomass & 154,286 & 20,140 & 38,434 & 5.38 \\
Personnel & & & 57,846 & 7.69 \\
Total & $1,697,148$ & 221,537 & 509,203 & 3.80 \\
\hline & & & 28,588 & 70.63 \\
\hline
\end{tabular}


gaseous mixture of methane, carbon dioxide and trace amounts of hydrogen sulfide and hydrogen is produced (Figure 5). Hence, AD systems are often referred to as "biogas systems". The composition of organic wastes most suitable for $\mathrm{AD}$ is not clear and varies from one literature source to another. All organic wastes contain proteins, fats, fibers and inert material that cannot be digested.

All biomass fractions with the exception of lignin can be degraded by anaerobic microbes, however a pre-treatment of lignocellulosic compounds is strongly recommended to make the cellulose and hemi-cellulose better available for the bacterial degradation. This pre-treatment might be enzymatic, chemical or physical. Dr. Ram Chandra [6] recommends thermal liquefaction method. The process is comparable to the initial hydrolysis for alcohol production from lignocellulosic material. The residues and waters after digestion contain dissolved organics and inorganics as well as non-digested solids. Depending on the feed, these residues can have a value as e.g. fertilizers or require other treatments prior to their disposal.

Refetrence [19] reviewed the cost of at least 11 biogas plants in Canada and the U.S. The systems were either mixed plug flow (MPF) or completely mixed digester (CMD). The capacity of the systems was expressed in maximum power generation in $\mathrm{kW}$, ranging from 120 to $600 \mathrm{~kW}$. The plot of capital cost in USD vs. power had a scale factor of 0.63 for the continuous stirred tank reactor (CSTR) and 0.87 for the MPF as follows:

CMD: Capital $=46,594(\mathrm{~kW})^{0.63}$; MPF: $7636(\mathrm{~kW})^{0.87}$.

The above scale equations suggests that MPF systems have a lower baseline capital cost but the cost increases with a lager exponent than the CMD system. According to Ref [19] there are also studies suggesting that the economic differences between the low-solids $\mathrm{CM}$ systems with complete mixing and the high-solids PF systems without mechanical devices within the reactor are small.

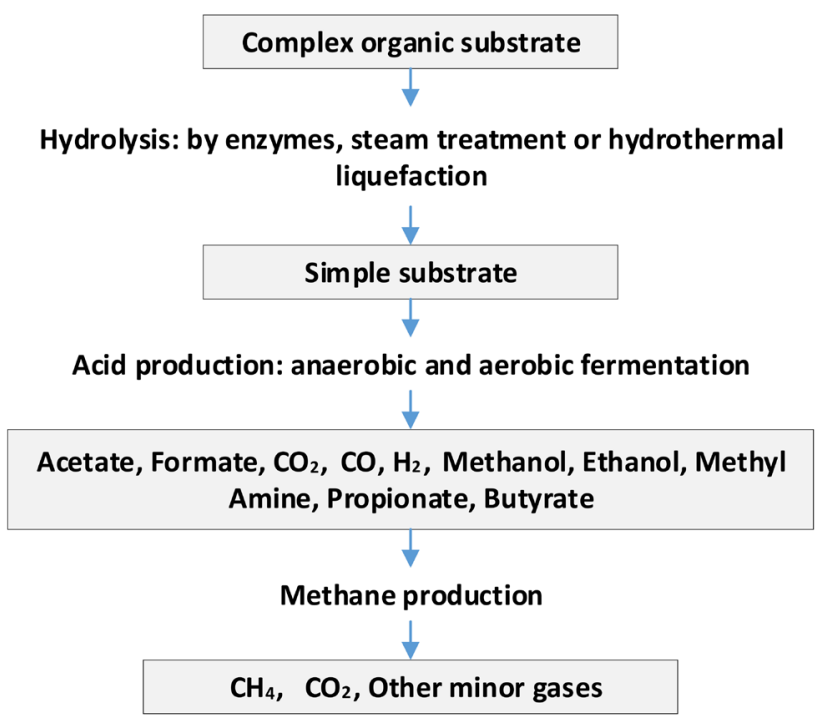

Figure 5. Raw biomass to biogas and bio-methane process [6] [20]. 
The mass population that are presently using bioenergy as the primary source of energy belongs to rural areas of the country. Reference [8] conducted a survey of household energy consumption pattern in the village of Jhajjhar district of Haryana in 2007. Dung cakes, crop residues and firewood were found to be the three main fuels used for cooking, though liquid petroleum gas (LPG) was also used along with crop residues. Income was an important factor determining the choice of fuel for cooking though a number of other socio-cultural factors were important in making fuel preferences at household level.

\section{Concluding Remarks}

After examination of several existing and promising biomass conversion technologies outlined in [20] [21] we concluded that a speedy cut and baling the left-over residue after combine will reduce the need of farmers to burn their residue. This will not happen unless a value proposition is created for the farmers. A pelleting plant will turn the biomass bales or chopped up stalks into pellets for storage and transport. The pellets will be available for applications like combustion for heat and power and biogas production. In future, the engineered pellets will meet stringent reaction specifications to produce advanced cellulosic liquid biofuels like ethanol, diesel and jet fuel with high conversion rates. The authors believe that these technologies will not come on stream without solving the variability in feedstock. Considerable research to date shows the pre-treatment of straw for initial hydrolysis can improve the efficiency of converting biomass to biogas and methane.

UNEP [20] published a monogram in 2013 titled "Technologies for converting waste agricultural biomass to energy". The publication outlined the state of biomass conversion technologies as presented in Figure 3. According to a more recent study conducted by IRENA [13], it appears there has not been much progress in biomass conversion technologies since 2013. The identified barriers against the commercialization of fuels from biomass and investment risks are persisting

The technologies that are fully commercialized to-date are related to biomass densification and combustion. These two technologies are fully at the readiness TR 8 and 9. Although, bio-char has been commercialized at a relatively small scale, problems with odor, emissions, and a potent dust are yet to be worked out. Anaerobic digestion is also a proven technology at a commercial scale in some parts of the world. The low calorific value biogas is mostly used in internal combustion engines to produce power.

The specific aspects of biogas that require further research relate to operating the gasifiers in cold climates and on selecting the blends of fibrous cellulosic material for its optimal conversion to biogas. The production of pyrolysis oil is commercialized but its full application except burning as a burner fuel has not been discovered. Although cellulosic bioethanol is claimed to be at the verge of commercialization [21], the evidence from pioneer plants in the U.S. shows that 
challenges in variability in feedstock properties [22] [23] that would lead to a low conversion rate yet to be overcome.

\section{Acknowledgements}

The authors acknowledge the financial support received from Ministry of $\mathrm{Hu}$ man Resource Development (MHRD), Government of India for the Project ID-904 under the Scheme for Promotion of Academic and Research Collaboration (SPARC) and support of the CCS Haryana Agricultural University, India and University of British Columbia, Canada.

\section{Conflicts of Interest}

The authors declare no conflicts of interest regarding the publication of this paper.

\section{References}

[1] Kothari, R., Vashishtha, A., Singh, H.M., Pathak, V., Tyagi, V., Yadav, B.C., Ashokkumar, V. and Singh, D.P. (2020) Assessment of Indian Bioenergy Policy for Sustainable Environment and Its Impact for Rural India: Strategic Implementation and Challenges. Environmental Technology \& Innovation, 20, Article ID: 101078. https://doi.org/10.1016/j.eti.2020.101078

[2] Datta, A., Emmanuel, M., Ram, N. and Dhingra, S. (2020) Crop Residue Management: Solution to Achieve Better Air Quality. The Energy and Resources Institute (TERI), New Delhi. http://www.teriin.org

[3] Sarkar, S., Skalicky, M., Hossain, A., Brestic, M., Saha, S., Garai, S., Ray, K. and Brahmachari, K. (2020) Management of Crop Residues for Improving Input, Use Efficiency and Agricultural Sustainability. Sustainability, 12, 9808. https://doi.org/10.3390/su12239808

[4] Government of Haryana (2018) Policy for Management and Utilization of Crop Residues in Haryana-Draft, Haryana, India. 11 p.

[5] EIA (2021) Analysis-Energy Sector Highlights. https://www.eia.gov/international/analysis/country/IND

[6] Chandra, R. (2019) Personal Communication. Centre for Rural Development and Technology, Indian Institute of Technology, New Delhi.

[7] Garg, M.K. (2019) Bioenergy Potential from Crop Residue Biomass in India. Slide Presentation. Department of Processing and Food Engineering, CCS HAU, Hisar.

[8] Joon, V., Chandra, A. and Bhattacharya, M. (2009) Household Energy Consumption Pattern and Socio-Cultural Dimensions Associated with It: A Case Study of Rural Haryana, India. Biomass \& Bioenergy, 33, 1509-1512. https://doi.org/10.1016/j.biombioe.2009.07.016

[9] Yoshida1, T., Nomura, T., Gensai, H., Watada, H., Sano, T. and Ohara, S. (2015) Upgraded Pellet Making by Torrefaction-Torrefaction of Japanese Wood Pellets. Journal of Sustainable Bioenergy Systems, 5, 82-88. https://doi.org/10.4236/jsbs.2015.53008

[10] Thengane, S.K., Kung, K.S., Gupta, A., Ateia, M., Sanchez, D., Mahajani, S.M., Lim, C.J., Sokhansanj, S. and Ghoniem, A. (2020) Oxidative Torrefaction for Cleaner Utilization of Biomass for Soil Amendment. Cleaner Energy and Technology, 1, Ar- 
ticle ID: 100033. https://doi.org/10.1016/j.clet.2020.100033

[11] Mehta, A.K., Sharma, M., Sharma, K. and Yadav, P. (2018) Report of the Task Force on Biomass Management. Confederation of Indian Industry (CII), The Mantosh Sondhi Centre, New Delhi. http://www.cii.in

[12] Landälv, I., Waldheim, L., Kyriakos, M., van den Heuvel, E. and Kalligeros, S. (2017) Building Up the Future Cost of Biofuel. Sub Group on Advanced Biofuels. Sustainable Transport Forum. European Commission. Directorate-General for Transport Unit MOVE.DDG1.B.4-Sustainable \& Intelligent Transport. Publications Office of the European Union, Luxembourg, 79 p.

[13] Kyriakos, M., Landälv, I., Waldheim, L., van den Heuvel, E. and Kalligeros, S. (2017) Building-Up the Future Technology Status and Reliability of the Value Chains. Sub Group on Advanced Biofuels. Sustainable Transport Forum. European Commission. Directorate-General for Transport Unit MOVE.DDG1.B.4-Sustainable \& Intelligent Transport. Publications Office of the European Union, Luxembourg, 79 p.

[14] Purohit, P. and Chaturvedi, V. (2018) Biomass Pellets for Power Generation in India: A Techno-Economic Evaluation. Environmental Science and Pollution Research, 25, 29614-29632. https://doi.org/10.1007/s11356-018-2960-8

[15] Jarno, F., Raghu, K.C., Karttunen, K. and Ranta, T. (2019) Impact of Alternative Raw Materials on the Profitability of a Large-Scale Bio-Coal Pellet Plant in Finland. Journal of Sustainable Bioenergy Systems, 9, 1-15. https://doi.org/10.4236/jsbs.2019.91001

[16] Obernberger, I. and Thek, G. (2010) The Pellet Handbook. The Production and Thermal Utilization of Biomass Pellets. IEA Bioenergy. Earthdcan, Washington DC, $549 \mathrm{p}$.

[17] Mani, S., Sokhansanj, S., Bi, X. and Turhollow, A. (2006) Economics of Producing Fuel Pellets from Biomass. Applied Engineering in Agriculture, 22, 421-426. https://doi.org/10.13031/2013.20447

[18] IRENA (2019) Advanced Biofuels. What Holds Them Back? International Renewable Energy Agency, Abu Dhabi, 79 p.

[19] Wang, Y. (2007) Development of an Analytical Tool for Anaerobic Digestion of Organic Wastes. Unpublished M.A.Sc. Thesis, Department of Chemical \& Biological Engineering, University of British Columbia, Vancouver.

[20] Sugathapala, A.G.T. (2013) Technologies for Converting Waste Agricultural Biomass to Energy United Nations Environmental Programme Division of Technology, Industry and Economics International Environmental Technology Centre Osaka. $212 \mathrm{p}$.

[21] IEA (2019) Bioenergy Task 39: Newsletter-Commercializing Conventional and Advanced Transport Biofuels from Biomass and Other Renewable Feedstocks. http://task39.sites.olt.ubc.ca/files/2019/08/IEA-Bioenergy-Task-39-Newsletter-Issue -52-1.pdf

[22] Ravichandran, P., Gibb, D. and Corscadden, K. (2013) Controlled Batch Leaching Conditions for Optimal Upgrading of Agricultural Biomass. Journal of Sustainable Bioenergy Systems, 3, 186-193. https://doi.org/10.4236/jsbs.2013.33026

[23] Smith, W.A., Gresham, G.L. and Westover, T. (2013) Understanding Biomass Feedstock Variability. Biofuels, 4, 111-127. https://doi.org/10.4155/bfs.12.83 